\title{
In vitro maturation of Mus musculus mice oocytes after hyperosmotic shock induced by vitrification solutions
}

\author{
Erica Koaski ${ }^{1}$, Cláudia Schneider Colle ${ }^{1}$, Rafael Alonso Salvador ${ }^{1}$, Vera Lucia Lângaro Amaral ${ }^{1}$, Alfred Paul Senn ${ }^{2}$, \\ David Til ${ }^{1}$
}

${ }^{1}$ Universidade do Vale do Itajaí (UNIVALI), Laboratory of Reproductive Biology, Itajaí/SC, Brasil

${ }^{2}$ Fertas Brasil, Balneário Camboriú/SC, Brasil

\begin{abstract}
Objective: To evaluate in vitro oocyte maturation rates in embryonic culture medium after induction by hyperosmotic shock caused by exposure to vitrification solutions.

Methods: Bilateral oophorectomy was performed on 20 prepubescent female mice (Swiss). Immature (Prophase I) oocytes $(\mathrm{N}=400)$ were obtained by ovarian dissection, divided into 4 groups, and transferred to culture dishes containing fertilization medium (Sydney IVF Fertilization Medium, Cook $^{\circledR}$ Medical). The control group (CG) did not receive treatment, the test groups (G1, G2, G3) were treated with vitrification solution - 2 (VI-2: 14 M sucrose + ethylene glycol and dimethyl sulfoxide) for 30 seconds and subsequently: G1: 30 seconds in devitrification solution 2 (DV-2: 0.5M sucrose); G2: 60 seconds DV-2; G3: 60 seconds DV-1(1M sucrose) and 180 seconds DV-2. All groups were cultivated for 24 hours in an incubator at $37^{\circ} \mathrm{C}$ and $5 \% \mathrm{CO} 2$ (Thermo model 3110 ). After this period, we checked their maturation status.
\end{abstract}

Results: Oocytes exposed to VI-2, DV-1 and DV-2 (G3) showed the highest rate of competence in resuming meiosis and reaching the MII stage; however, there was no statistically significant difference (G3 $=50.5 \%-49 / 97$; CG $=27.8 \%-10 / 30$ ).

Conclusions: Oocyte exposure to vitrification solutions, in order to cause osmotic shock, did not interfere with the resumption of meiosis in mice oocytes.

Keywords: Oocyte maturation, oocytes, hyperosmotic shock, meiosis resumption, mice

\section{INTRODUCTION}

Despite the significant progress of cancer treatments, the quality of patients' survival may be reduced by the occurrence of early gonad functional failure, leading to infertility (Matos et al., 2012; Mandinka et al., 2014). Consequently, the concern with the quality of life after cancer treatment boosted the exploration of means to preserve fertility, especially among younger patients who might be adversely affected before having given birth to an offspring or reached reproductive age (Carvalho, 2015). Using assisted reproduction techniques, it is now possible to induce viable pregnancies in infertile patients (Félis \& Almeida, 2016), but also to preserve fertility in oncological patients undergoing chemotherapy or radiotherapy treatments (Tomás et al., 2016).

In adult patients, fertility preservation may be achieved through cryopreservation of embryos, oocytes or ovarian tissue (Carvalho et al., 2017; Matos et al., 2011). In prepubescent girls or in adult females who cannot receive hormonal stimulation due to the development of hormonedependent tumors, leukemia or advanced diseases (Tomás et al., 2016), cryopreservation of ovarian tissue is the only option (Mendonça et al., 2014). This technique still present some risks such as tissue ischemia or the development of tumors after reimplantation (Rosa e Silva, 2006). In this context, the collection of immature oocytes (in prophase I) for in vitro maturation (IVM) becomes an option that eliminates most of the disadvantages when compared to the existing approaches, since it is not necessary to suspend chemotherapy treatment, it does not require a partner or semen donor, and the patient does not need to have gone through puberty (Rosa e Silva, 2006).

The purpose of IVM is to simulate the in vivo process, giving the oocytes the necessary growth factors and hormones in order to allow them to restart meiosis and reach the metaphase II stage (Watson, 2007; Xu et al., 2009). Around birth, female germ cells are arrested in prophase of the first meiotic division. The oocytes remain blocked, until they are stimulated to mature and grow, an event that starts at puberty (Frantz et al., 2006). In vivo, the resumption of meiosis occurs through the action of the luteinizing hormone (LH), whereas, in vitro, it is only necessary to remove the oocyte from the follicle, in order to initiate nuclear maturation (Dekel et al., 1981).

Animal models provide useful information on the way substances may inhibit oocyte maturation, such as cyclic adenosine monophosphate (CAMP), or positively affect cell cycle, like proteins, growth factors, GnRH, purines, steroids, gonadotropins (Dieleman et al., 2002). The Ca2+ chelators block germinal vesical break down in mammalian oocytes at least up to the first metaphase. Furthermore, in absence of intracellular $\mathrm{Ca} 2+$ elevation, spontaneous meiosis resumption in vitro does not occur (Molina et al., 2016). Moreover, it has been demonstrated for Jones et al. (1995) that the injection of $\mathrm{Ca} 2+$ in mice oocytes induces parthenogenetic activation and subsequent normal embryo development. It is currently known that cryoprotectants such as dimethyl sulphoxide (DMSO) and ethylene glycol (EG) improve calcium transport in several cell lines (Castro et al., 2011). DMSO is known also to act on the release of calcium from intracellular storages and EG on its influx (Larman et al., 2006), which suggests that these compounds might be beneficial for oocyte maturation in vitro. IVM protocols have changed little over the past decades, and there is a growing interest in the clinical application of this technique in assisted reproduction (Coticchio et al., 2012).

The aim of this study is to evaluate the effect of hyperosmotic shock, caused by short exposure to cryopreservation solutions of immature oocytes from prepubescent mice, on the rates of oocyte maturation in vitro.

\section{MATERIAL AND METHODS}

Animal experimentations were performed while respecting the norms recommended by the Brazilian Society of Science with Laboratory Animals (SBCAL) and 
the National Council of Control of Animal Experimentation (CONCEA). The experimental protocol was approved by the Ethics Committee for the Use of Animals of the Universidade do Vale do Itajaí (CEUA/UNIVALI) under protocol number 069/17.

Twenty prepuberal female mice (Mus musculus) of the Swiss lineage, 4 to 6 weeks old, were obtained from the Central Vivarium of the Universidade do Vale do Itajaí. The animals were kept in groups of 5 in polypropylene boxes, containing wood shavings and environmental enrichments (paper towels, boxes, rolls, and paper reels) in order to promote their well-being. Room temperature was maintained at $22 \pm 2^{\circ} \mathrm{C}$, under a photoperiod of 12 hours (light/dark). Water and food were provided ad libitum.

To perform bilateral oophorectomy, the female mice were slaughtered in a $\mathrm{CO} 2 / \mathrm{O} 2$ chamber (Walls et al., 2015) using a proportion of $30 \%$ of $\mathrm{CO} 2$ and $70 \%$ of $\mathrm{O} 2$, aiming to reduce suffering, as recommended by the Ethics Committee for the Use of Animals. The ovaries were collected in a Petri dish containing buffered medium (GV-Hepes, Ingámed ${ }^{\circledR}$, Maringá/PR, Brazil) and sectioned radially with a microneedle $(0.45 \times 13 \mathrm{~mm}, \mathrm{BD}$ Medical, Brazil). The released immature oocytes were then retrieved and selected using a stereomicroscope (40x, Olympus SZ, Japan) based on their spherical shape, homogeneous cytoplasm, and lack of inclusions. The oocytes were immediately transferred to culture dishes (35 $\mathrm{mm}$ diameter, Ingámed ${ }^{\circledR}$, Maringá/PR, Brazil) containing microdroplets of pre-equilibrated $\left(5 \% \mathrm{CO} 2,37^{\circ} \mathrm{C}\right)$ culture medium (Sydney IVF Fertilization Medium, CookMedical ${ }^{\circledR}$, Australia).

We then divided the oocytes into 4 groups ( $C G n=108$, G1 $n=98, G 2 n=97, G 3 n=97$ ). The experimental groups were exposed to vitrification/devitrification solutions for different time durations (Figure 1). Vitrification (VI2 , containing $0.5 \mathrm{M}$ sucrose, $15 \% \mathrm{EG}$, and $15 \% \mathrm{DMSO})$ and devitrification (DV-1, containing $1 \mathrm{M}$ sucrose; DV-2, containing $0.5 \mathrm{M}$ sucrose) solutions were obtained from Ingámed ${ }^{\circledR}$. The control group (CG) was placed directly in culture without exposure to cryoprotectants. The G1 group was exposed to VI-2 (30 sec) followed by DV-2 (30 sec). The G2 group was exposed to VI-2 (30 sec) and to DV-2 (60 $\mathrm{sec})$. The G3 group was exposed to VI-2 (30 sec), followed by DV-1 $(60 \mathrm{sec})$ and DV-2 (180 sec). All groups were then cultivated for $24 \mathrm{~h}$ at $37^{\circ} \mathrm{C}$ under $5 \%$ CO2 (Thermo model 3110, Thermo Fisher Scientific, United States). After this period, we checked the oocyte maturation status.

The characteristics indicative of nuclear maturation were scored as follows: 1) prophase I, presence of germinal vesicle (VG), 2) first meiotic metaphase (MI), absence of the nuclear membrane, 3) second meiotic metaphase (MII), presence of the first polar body in the perivitelline space (Setti et al., 2011). The following morphological aspects were also recorded: ooplasm sphericity, cytoplasm homogeneity, and the presence of inclusions. Oocyte morphology was good when the oocyte had a spherical shape and a homogeneous cytoplasm without inclusions (Setti et al., 2011). Calculated survival rates were based on oocytes with good morphology, observed only under the microscope, without any type of staining, throughout the IVM process. We calculated the rates of oocyte maturation reaching the stages of MI and MII after $24 \mathrm{~h}$.

We assessed the results by analyzing the ANOVA variance with the Tukey's post-test (GraphPad software for Windows, San Diego, USA), and the differences were considered significant when $p<0.05$.

\section{RESULTS}

Table 1 depicts the rates of oocytes maturation to MII stages. In the control group, $27.8 \%$ of immature oocytes reached the MII stage after $24 \mathrm{~h}$ of IVM. In the G1, G2 and $\mathrm{G} 3$ groups the maturation rates were significantly higher $(p<0.05)$ compared to the control group and reached $49.0 \%, 44.3 \%$, and $50.5 \%$, respectively. Among the treated groups, G3 produced higher maturation rates than G1 and G2, but with no statistically significant difference between the groups.

The percentage of survival was also determined for all groups, and the results are presented in Table 2 . In the control group, the result was $92.6 \%$ (100 oocytes survived out of 108), G1 had a result of $91.8 \%(90 / 98)$; G2 presented a rate of $94.8 \%(92 / 97)$ and the rate of G3 was $95.9 \%$ (93/97). There were no significant differences between the groups.

\section{DISCUSSION}

Our results showed that a hyperosmotic shock, induced by short exposure of immature oocytes to vitrification and devitrification solutions, is able to significantly improve in vitro maturation up to the MII stage. The prepubescent mice used in this study were not submitted beforehand to ovarian hyperstimulation, since we wanted to simulate the situation in which the patients would not receive any type of hormonal treatment. The fact that IVM results are not influenced by a preparatory ovarian stimulation has been recognized since early trials (Hatırnaz et al., 2018; Söderström-Anttila et al., 2005), and this suggests that the activation mechanism of oocyte maturation is not solely controlled by endocrine mechanisms.

Another important finding of our study is that the osmotic treatment with commercially available vitrification solutions has no impact on the survival rates of the oocytes during the $24 \mathrm{~h}$ of in vitro maturation. In our protocol, the exposure to the vitrification solution was reduced to a short $(30 \mathrm{sec})$ treatment with the most concentrated vitrification solution (containing $1.4 \mathrm{M}$ sucrose). In these conditions, the oocytes are submitted to important osmotic stress, but this did not notably increase lethal cellular injury as one might have expected (Elliott et al., 2017). Immature silver fox oocytes were shown to mature equally well, independently whether they were primarily exposed or not to an equilibrium solution before being exposed to the vitrification solution (Cao et al., 2017). Similar observations were made with human immature oocytes from IVF patients which matured better after the hyperosmotic shock, induced by vitrification solutions (Molina et al., 2016).

Our observations on oocytes in vitro maturation from prepubescent mice ovaries behaved similarly to those from adults in other species, probably because they are under the control of similar mechanisms. The most prominent candidate is calcium. Meiosis resumption occurs mainly following an increase in intracellular calcium (Carafoli, 2002). Both cryoprotective substances present in the vitrification medium used in this study have the capacity to enhance calcium exchanges, DMSO acting on the intracellular concentrations, while EG promotes calcium influx from the external medium (Larman et al., 2006). The intracellular $\mathrm{pH}$ and calcium oscillations induced by the vitrification solution are likely to be tightly associated during oocyte maturation and fertilization. In the oocyte, the $\mathrm{pH}$ regulating mechanism seems first at rest and it then becomes activated during maturation and fertilization (FitzHarris \& Baltz, 2009). Some pH regulators are sensitive to calcium (or its pathways) because the reactivation of $\mathrm{pH}$ regulation corresponds to the beginning of ion oscillations (Jones et al., 1995; Marangos et al., 2007). Thus, pH homeostasis and regulation are essential partners of calcium during oocyte growth and maturation (FitzHarris \& Baltz, 2009). 


\section{Immature oocyte collection}

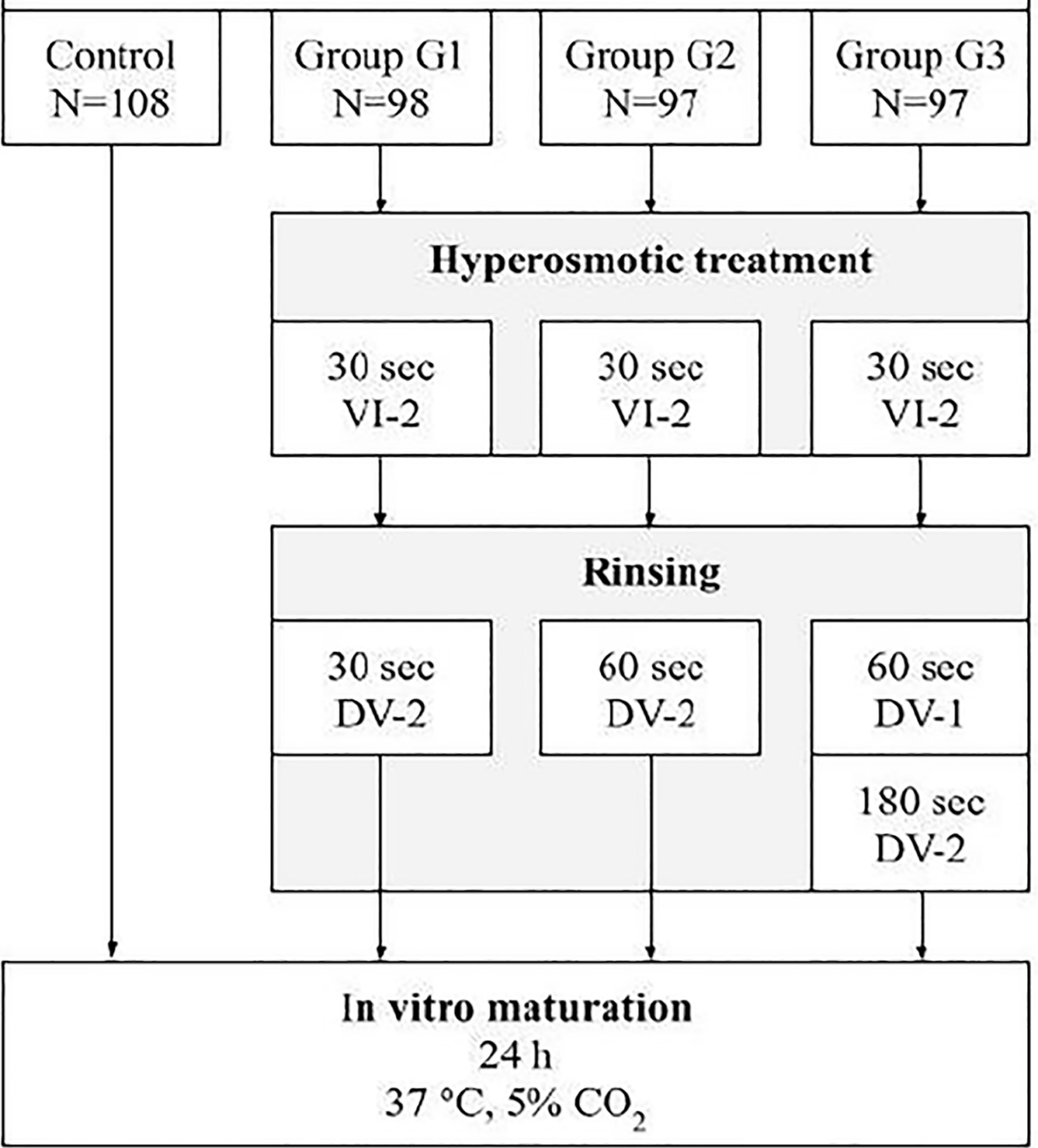

Figure 1. Scheme of the methodology used in the study. In vitro oocyte maturation was performed in microdroplets of $30 \mu \mathrm{L}$ of Sydney IVF Fertilization Medium at $37{ }^{\circ} \mathrm{C}, 5 \% \mathrm{CO}_{2}$ and high humidity. VI-2: vitrification solution, DV-1, and DV-2: devitrification solutions containing $1 \mathrm{M}$ and $0.5 \mathrm{M}$ sucrose respectively (Ingámed ${ }^{\circledR}$ ) were used to induce a temporary hyperosmotic shock. N: number of immature oocytes in each group.

The process of dehydration-rehydration used in this study is controlled by the selective permeability of the plasma membrane to permeant cryoprotectants (Castro et al., 2011) and non-permeant substances able to generate an osmotic gradient (Finan \& Guilak, 2010). During devitrification, cryoprotectants are removed, and the cell recovers its volume through the influx of water until osmotic equilibrium is reached (Ambrosini et al., 2006; Si et al., 2006). Type and concentration of cryoprotectants, exposure time and medium temperature are critical factors that affect the viability of these processes (Liu et al., 2012).

Our study highlights a third important aspect associated with the rehydration process. As shown in Table 1, oocytes from $\mathrm{G} 3$ had the highest maturation rate compared to the 
Table 1. Oocyte maturation rates of the control group and experimental groups (G1, G2, and G3) after hyperosmotic shock, induced by exposure to vitrification solutions. MII: number ( $n$ ) of oocytes reaching the MII stages after $24 \mathrm{~h}$ IVM. MI: number of oocytes $(n)$ that reached the MI stage at some time point during IVM, this value includes both those, which remained at the MI stage after $24 \mathrm{~h}$, and those, which reached the MII stage. $\mathrm{N}$ : total number of cultivated oocytes in each group.

\begin{tabular}{|l|l|}
\hline Group & MII \% (n/N) \\
\hline CONTROL & $27.8(30 / 108)^{*}$ \\
\hline G 1 & $49.0(48 / 98)^{*}{ }^{+}$ \\
\hline G 2 & $44.3(43 / 97)^{*}{ }^{+}$ \\
\hline G 3 & $50.5(49 / 97)^{*},{ }^{+}$ \\
\hline
\end{tabular}

* Significant differences $(p<0.05)$ between control and treated groups.

${ }^{+}$no significant differences between groups.

Table 2. Survival rates of mouse oocytes. Number of intact oocytes $(n)$ after $24 \mathrm{~h}$ of IVM. N: total number of cultivated oocytes in each group.

\begin{tabular}{|l|c|}
\hline N: total number of cultivated oocytes in each group. Groups & Survival rate \% $(\mathrm{n} / \mathrm{N})$ \\
\hline CONTROL & $92.6(100 / 108)^{+}$ \\
\hline G 1 & $91.8(90 / 98)^{+}$ \\
\hline G 2 & $94.8(92 / 97)^{+}$ \\
\hline G 3 & $95.9(93 / 97)^{+}$ \\
\hline
\end{tabular}

${ }^{+}$no significant differences between groups.

control or to groups 1 and 2. The particular aspect of G3 is that the rehydration, following the hyperosmotic shock, was performed in two steps. It thus appears that the recovery of an iso-osmotic equilibrium with the culture medium is a sensitive process that cannot be solely controlled by time as it involves also thorough and gentle removal of the largest possible portion of the cryoprotectants.

The successful spontaneous maturation of control oocytes (GC) is likely due to the dismantling of the cumulus oophorus, and rupturing of the gap-junctions (Vozzi et al., 2001), which occur during the collection procedure (Thomas et al., 2004). The mechanical recovery of oocytes leads to the recovery of a heterogeneous population of immature oocytes, and the osmotic-shock induced oocyte maturation probably acts on a subpopulation of oocytes that are not activated by the simple dissociation of the cumulus cells.

However, oocyte exposure to cryoprotectants leads to the hardening of the zona pellucida (Larman et al., 2006; Matson et al., 1997). This is due to the conversion of the zona pellucida glycoprotein (ZP2) into a modified form that is induced by the calcium surge. This phenomenon is normally present after fertilization in order to harden the zona pellucida and prevent polyspermy (Rogers et al., 2018). For reproductive purposes, this problem can be circumvented by intracytoplasmic injection (ICSI), which has become a technique of choice for cryopreserved oocytes, since it yields a higher fertilization rate than conventional in vitro fertilization (IVF) (Kazem et al., 1995).

Regarding toxicity, another negative effect of cryoprotectants (EG and DMSO) is the generation of free radicals (Best, 2015). Antioxidant treatments have been shown to reduce the oxidative damage during the vitrification of immature oocytes in mice (Moawad et al., 2014) and pigs (Gupta et al., 2010), which suggests that these substances might become routinely used to prevent oxidative damages by cryoprotectants in the future.
Finally, large oscillations in the oocyte maturation responses were observed from one experiment to another (Figure 2). Many factors may be involved in these alterations, such as the status of each animal, environmental alteration, management practices, temperature, feeding, and water intake. The induction of chronic stress in animals is known to trigger a series of hormonal alterations, and cause reproductive problems (Macedo et al., 2012; Macfarlane et al., 2000). Larger temporal trends during winter and summer are also known to affect maturation rates in bovines (Pavani et al., 2017), but most of these effects should have been controlled in our animal facilities.

\section{CONCLUSION}

In conclusion, the use of commercially available vitrification solutions to induce a hyperosmotic shock

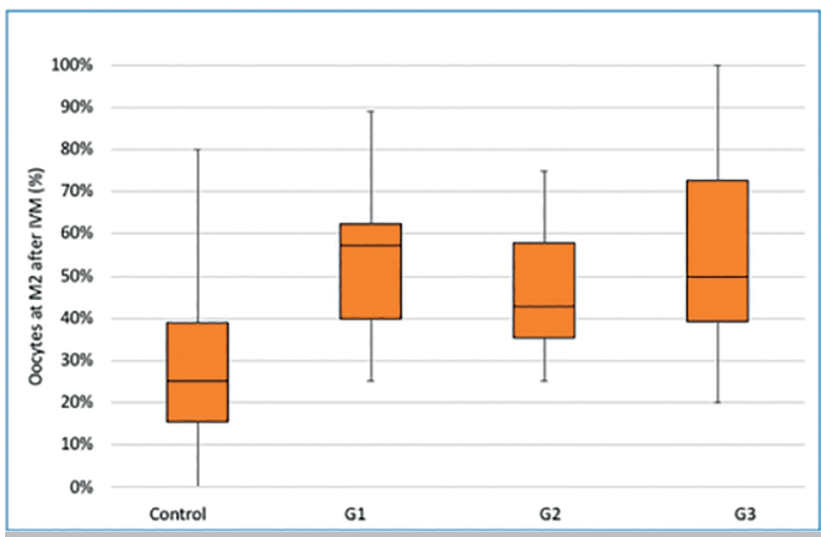

Figure 2. Box and whiskers plot of the percentage of oocyte reaching the metaphase II stage in the 4 groups tested in 11 repeats of the experiments. Control: no treatment, G1, G2, G3: treated groups (see figure 1). Boxes represent p25, p50, and p75; whiskers indicate positions of minimum and maximum values. 
did not interfere with the resumption of meiosis in mice oocytes. Further studies are needed to better explain the biological mechanisms involved, to reduce collateral damages caused by the cryoprotectants and to check the ability of such in vitro matured oocytes to fertilize.

\section{ACKNOWLEDGMENTS}

We thank everyone who collaborated effectively or intellectually to make this study happen, and in particular aides and professionals from the Reproduction Biotechnology Laboratory of Univali who actively contributed with teaching and assisting in the techniques.

\section{CONFLICT OF INTEREST}

The authors report no conflicts of interest.

\section{Corresponding author:}

Érica Koaski

Universidade do Vale do Itajaí (UNIVALI)

Laboratory of Reproductive Biology

Itajaí/SC, Brasil

Email:koaskierica@gmail.com

\section{REFERENCES}

Ambrosini G, Andrisani A, Porcu E, Rebellato E, Revelli A, Caserta D, Cosmi E, Marci R, Moscarini M. Oocytes cryopreservation: state of art. Reprod Toxicol. 2006;22:250-62. PMID: 16787736 DOI: 10.1016/j.reprotox.2006.04.024

Best BP. Cryoprotectant toxicity: facts, issues, and questions. Rejuvenation Res. 2015;18:422-36. PMID: 25826677 DOI: $10.1089 /$ rej.2014.1656

Cao X, Li J, Xue H, Wang S, Zhao W, Du Z, Yang Y, Yue $Z$. Effect of vitrification on meiotic maturation, mitochondrial distribution and glutathione synthesis in immature silver fox cumulus oocyte complexes. Theriogenology. 2017;91:104-11. PMID: 28215674 DOI: $10.1016 / j$.theriogenology.2016.12.037

Carafoli E. Calcium signaling: a tale for all seasons. Proc Natl Acad Sci U S A. 2002;99:1115-22 PMID: 11830654 DOI: $10.1073 /$ pnas.032427999

Carvalho BR. Oncofertilidade: bases para a reflexão bioética. Reprod Clim. 2015;30:132-9. DOI: 10.1016/j.recli.2015.11.003

Carvalho BR, Caetano JP, Cavagna M, Marinho RM, Silva AA, Nakagawa HM. Indução de ovulação em pacientes com tumor estrogênio-dependente: diretrizes clínicas da Sociedade Brasileira de Reprodução Humana. Reprod Clim. 2017;32:31-8. DOI: 10.1016/j.recli.2016.02.001

Castro SV, Carvalho AA, Silva CM, Faustino LR, Figueiredo JR, Rodrigues AP. Intracellular cryoprotectant agents: characteristics and use of ovarian tissue and oocyte cryopreservation. Acta Sci Vet. 2011;39:1-17.

Coticchio G, Dal-Canto M, Guglielmo MC, Mignini-Renzini $M$, Fadini R. Human oocyte maturation in vitro. Int J Dev Biol. 2012;56:909-18. PMID: 23417413 DOI: 10.1387/ ijdb.120135gv

Dekel N, Lawrence TS, Gilula NB, Beers WH. Modulation of cellto-cell communication in the cumulus-oocyte complex and the regulation of oocyte maturation by LH. Dev Biol. 1981;86:35662. PMID: 6793428 DOI: 10.1016/0012-1606(81)90193-7
Dieleman SJ, Hendriksen PJ, Viuff D, Thomsen PD, Hyttel $P$, Knijn HM, Wrenzycki C, Kruip TA, Niemann H, Gadella BM, Bevers MM, Vos PL. Effects of in vivo prematuration and in vivo final maturation on developmental capacity and quality of pre-implantation embryos. Theriogenology. 2002;57:5-20. PMID: 11775980 DOI: $10.1016 /$ S0093$691 \times(01) 00655-0$

Elliott GD, Wang S, Fuller BJ. Cryoprotectants: a review of the actions and applications of cryoprotective solutes that modulate cell recovery from ultra-low temperatures. Cryobiology. 2017;76:74-91. PMID: 28428046 DOI:10.1016/j. cryobiol.2017.04.004

Félis KC, Almeida RJ. Perspectiva de casais em relação à infertilidade e reprodução assistida: uma revisão sistemática. Reprod Clim. 2016;31:105-11. DOI:10.1016/j.recli.2016.01.004

Finan JD, Guilak F. The effects of osmotic stress on the structure and function of the cell nucleus. J Cell Biochem. 2010;109:460-7. PMID: 20024954 DOI: 10.1002/ jcb. 22437

FitzHarris G, Baltz JM. Regulation of intracellular pH during oocyte growth and maturation in mammals. Reproduction. 2009;138:619-27. PMID: 19520797 DOI: 10.1530/REP$09-0112$

Frantz N, Bos-Mikich A, Ferreira MO, Frantz GN, Oliveira NP. Origem, crescimento, degeneração e maturação in vitro do oócito. Femina. 2006;34:537-43.

Gupta MK, Uhm SJ, Lee HT. Effect of vitrification and beta-mercaptoethanol on reactive oxygen species activity and in vitro development of oocytes vitrified before or after in vitro fertilization. Fertil Steril. 2010;93:2602-7. PMID: 20303480 DOI: $10.1016 /$ j.fertnstert.2010.01.043

Hatırnaz Ş, Ata B, Hatırnaz ES, Dahan MH, Tannus S, Tan J, Tan SL. Oocyte in vitro maturation: a sytematic review. Turk J Obstet Gynecol. 2018;15:112-25. PMID: 29971189 DOI: $10.4274 /$ tjod.23911

Jones KT, Carroll J, Whittingham DG. Ionomycin, thapsigargin, ryanodine, and sperm induced $\mathrm{Ca} 2+$ release increase during meiotic maturation of mouse oocytes. J Biol Chem. 1995;270:6671-7. PMID: 7896808 DOI: 10.1074/ jbc.270.12.6671

Kazem R, Thompson LA, Srikantharajah A, Laing MA, Hamilton MP, Templeton A. Cryopreservation of human oocytes and fertilization by two techniques: in-vitro fertilization and intracytoplasmic sperm injection. Hum Reprod. 1995;10:2650-4. PMID: 8567786 DOI: 1093/oxfordjournals.humrep.a135761

Larman MG, Sheehan CB, Gardner DK. Calcium-free vitrification reduces cryoprotectant-induced zona pellucida hardening and increases fertilization rates in mouse oocytes. Reproduction. 2006;131:53-61. PMID: 16388009 DOI: $10.1530 /$ rep. 1.00878

Liu J, Phy J, Yeomans E. Theoretic considerations regarding slow cooling and vitrification during cryopreservation. Theriogenology. 2012;78:1641-52. PMID: 22818092 DOI: $10.1016 /$ j.theriogenology.2012.05.003 
Macedo GG, Zúccari CE, Costa e Silva EV. Effects of stress on reproductive performance of female bovine. Rev Bras Reprod Anim. 2012;36:10-7.

Macfarlane MS, Breen KM, Sakurai H, Adams BM, Adams TE. Effect of duration of infusion of stress-like concentrations of cortisol on follicular development and the preovulatory surge of LH in sheep. Anim Reprod Sci. 2000;63:167-75. PMID: 10989227 DOI: 10.1016/S0378-4320(00)00179-2

Marangos $\mathrm{P}$, Verschuren EW, Chen R, Jackson PK, Carroll J. Prophase I arrest and progression to metaphase I in mouse oocytes are controlled by Emi1-dependent regulation of APCCdh1. J Cell Biol. 2007;176:65-75. PMID: 17190794 DOI: $10.1083 /$ jcb. 200607070

Matos MC, Bezerra MB, Vicent WR. Cryopreservation and xenotransplantation of ovarian tissue. Rev Bras Reprod Anim. 2011;35:467-71.

Matos MJ, Torres I, Sousa S, Freitas P, Carvalho D. Preservação da fertilidade na mulher com cancro. Rev Port Endocrinol Diabetes Metabol. 2012;7:44-51. DOI: 10.1016/ S1646-3439(12)70009-3

Matson PL, Graefling J, Junk SM, Yovich JL, Edirisinghe WR. Cryopreservation of oocytes and embryos: use of a mouse model to investigate effects upon zona hardness and formulate treatment strategies in an in-vitro fertilization programme. Hum Reprod. 1997;12:1550-3. PMID: 9262294 DOI: $10.1093 /$ humrep/12.7.1550

Mendonça M, Santos CR, Oliveira GS, Soares GC, Silva IL, Guerra MB, Silva MF. Repercussões do tratamento quimioterápico sobre a função ovariana. J Bras Med. 2014;102:38-41.

Moawad AR, Xu B, Tan SL, Taketo T. I-carnitine supplementation during vitrification of mouse germinal vesicle stage-oocytes and their subsequent in vitro maturation improves meiotic spindle configuration and mitochondrial distribution in metaphase II oocytes. Hum Reprod. 2014;29:2256-68. PMID: 25113843 DOI: 10.1093/humrep/deu201

Molina I, Gómez J, Balasch S, Pellicer N, Novella-Maestre E. Osmotic-shock produced by vitrification solutions improves immature human oocytes in vitro maturation. Reprod Biol Endocrinol. 2016;14:27. PMID: 27170005 DOI: $10.1186 / \mathrm{s} 12958-016-0161-1$

Pavani KC, Rocha A, Baron E, Lourenço J, Faheem M, Silva FM. The effect of kinetic heat shock on bovine oocyte maturation and subsequent gene expression of targeted genes. Zygote. 2017;25:383-9. PMID: 28592345 DOI: $10.1017 /$ S0967199417000223
Rogers KD, Foster BA, Guiterrez EJ, Diaz FA, Bondioli KR. Effects of dimethyl sulfoxide- or glycerol-based vitrification protocols on zona pellucida hardening in mature bovine oocytes. Reprod Fertil Dev. 2018;30:160. DOI: 10.1071/RDv30n1Ab41

Rosa e Silva AC. Fertility preservation. Rev Bras Ginecol Obstet. 2006;28:365-72. DOI: 10.1590/S010072032006000600008

Setti AS, Braga DP, Figueira RC. Punção folicular e classificação oocitária. In: Borges Junior E, Farah LMS, Cortezzi SS, eds. Reprodução humana assistida. São Paulo: Editora Atheneu; 2011. p. 63-72.

Si W, Benson JD, Men H, Critser JK. Osmotic tolerance limits and effects of cryoprotectants on the motility, plasma membrane integrity and acrosomal integrity of rat sperm. Cryobiology. 2006;53:336-48. PMID: 17084388 DOI: 10.1016/j.cryobiol.2006.09.001

Söderström-Anttila $V$, Mäkinen $S$, Tuuri T, Suikkari AM. Favourable pregnancy results with insemination of in vitro matured oocytes from unstimulated patients. Hum Reprod. 2005;20:153440. PMID: 15695312 DOI: 10.1093/humrep/deh768

Thomas RE, Armstrong DT, Gilchrist RB. Bovine cumulus cell-oocyte gap junctional communication during in vitro maturation in response to manipulation of cell-specific cyclic adenosine 3',5'-monophosophate levels. Biol Reprod. 2004;70:548-56. PMID: 14568915 DOI: 10.1095/biolreprod.103.021204

Tomás C, López B, Bravo I, Metello JL, Melo PS. Fertility preservation in oncologic patients or undergoing gonadotoxic therapies: state of art. Reprod Clim. 2016;31:55-61. DOI: $10.1016 /$ j.fertnstert.2013.08.012

Vozzi C, Formenton A, Chanson A, Senn A, Sahli R, Shaw $P$, Nicod P, Germond M, Haefliger JA. Involvement of connexin 43 in meiotic maturation of bovine oocytes. Reproduction. 2001;122:619-28. PMID: 11570969 DOI: 10.1530/ rep. 0.1220619

Walls ML, Douglas K, Ryan JP, Tan J, Hart R. In-vitro maturation and cryopreservation of oocytes at the time of oophorectomy. Gynecol Oncol Rep. 2015;13:79-81. PMID: 26425730 DOI: $10.1016 /$ j.gore.2015.07.007

Watson AJ. Oocyte cytoplasmic maturation: a key mediator of oocyte and embryo developmental competence. J Anim Sci. 2007;85:E1-3. PMID: 17322120 DOI: 10.2527/jas.2006-432

Xu M, Barrett SL, West-Farrell E, Kondapalli LA, Kiesewetter SE, Shea LD, Woodruff TK. In vitro grown human ovarian follicles from cancer patients support oocyte growth. Hum Reprod. 2009;24:2531-40. PMID: 19597190 DOI: 10.1093/humrep/dep228 